\title{
Do They Use Anything Other Than Google?
}

\author{
Sarah Crofts
}

Information \& Library Services

One of my teaching sessions for the first year law course, Legal Method, covers finding resources for law on the Internet. To make the seminar more interactive, I ask the students about the way they search the Internet and search engines they use.

In 2009-10 around 115 students attended the seminars and, of this number, few students said that they used any search engine other than Google. Yahoo and Ask Jeeves were the other choices. As with any subject, it is important to use reputable sources for legal research. There is evidence that it is not only students who rely on Google for their research; research by the Law Society's Gazette found that all levels of solicitors were using sources such as Wikipedia in preference to specialist law resources (Rayner 2008). This scenario is not just confined to students at the University of Greenwich. The existence of the so called 'Google effect' on 'the Google' or 'net generation' impacts upon almost all learners brought up with the World Wide Web (Downes 2007).

One student said that she always went to Google first with any new topic. Another said that at first she did not understand why she could not access Lexis with her university login when she found their website on Google, not realising that she needed to log in to the portal in order to access information in all the subscription databases via single sign-on authentication.

Although they are keen users of Google, few of the students were aware of other tools provided by Google such as advanced search, Google scholar, news search, search UK pages only. Everyone knew about enclosing phrases in quote marks to find the words in that exact order, for example, 'assisted suicide' but most were not aware of other basic search tools such as the OR connector to find any of the words in a search, for example 'assisted suicide' OR euthanasia OR 'mercy killing', outlined in the Google web search help pages: www.google.com/support/websearch.

It became apparent that many had used Google scholar even if they did not recognise the name. This can be a very useful way of finding articles quickly, but there are key disadvantages, such as the need to be on campus or logged in to the portal to see full text articles, as well as the distinct possibility that articles could be missed by not searching individual databases.

I also asked the students how they chose their search terms when using Google. Most said that they entered one or two keywords or a case name, although one student said that she always entered her entire essay title and was always very happy with the results. I suggested that there might be disadvantages with this approach, for example she might miss other items which have different keywords not in the title, or items in databases not indexed with many keywords which would ensure 
that they appear at the top of the search. All students agreed that they would not look beyond the first page of results of a Google search. Some acknowledged that searches for case names in the style "R $v$ Smith" rarely produced good results because of the multitude of similar results, often citations in articles or books, teachers' slides or notes.

An understanding of the way Google carries out searches may help explain to searchers why they do not retrieve the required results. Much information is buried in the 'invisible web' such as the content of databases or deep websites and other information which may not be found easily because of their format.

Devine and Egger-Sider (2009) have analysed the reasoning behind this. Database content may not be found because database records are dynamically created and results are not stored with a permanent url. Web crawlers generally do not find this information. Deep websites, such as government websites, have many levels of information beyond the reach of web crawlers. Other formats such as images and audio or video files may require specialist search engines.

Our students may appear to be confident and sophisticated in their use of the Web, but their searching is often limited to a small range of free resources. The influential CIBER report recognised that users are "increasingly looking for "the answer" and that the search engine "becomes the primary brand that they associate with the internet" $(2008: 8,12)$. They often prefer to use these free sources rather than the library databases which do not have the familiarity of Google. If these do not provide the expected results, they often give up early on. An independent Committee of Inquiry into the Changing Learner Experience (CLEX 2009: para 39) came to similar conclusions noting that, "Students tend to go no further than the first page or so of a website and, if they don't find what they're looking for there, they move on to another."

What do we do about this? Do we:

- Continue with our digital/information literacy work with students as part of their academic work? The independent Committee of Inquiry into the Changing Learner Experience suggest that higher education institutions "treat information literacies as a priority area and support all students so that they are able, amongst other things, to identify, search, locate, retrieve and, especially, critically evaluate information from the range of appropriate sources - web-based and other - and organise and use it effectively, attributed as necessary, in an appropriate medium" (CLEX 2009: section 7).

- Make search simpler - convert library catalogues and databases to a simple, single search Google style interface? Academic libraries and database providers are increasingly looking at ways of providing additional, simpler ways of searching by means of federated search and discovery tools.

My view is that we should pursue both options; what do others think? 


\section{References}

CIBER. (2008). Information behaviour of the researcher of the future. University College London. [Online]. Available at: www.ucl.ac.uk/infostudies/research/ciber/downloads/ggexecutive.pdf (accessed 26 May 2010).

Committee of Inquiry into the Changing Learner Experience. (2009). Higher Education in a Web 2.0 world. JISC. [Online]. Available at: www.jisc.ac.uk/publications/generalpublications/2009/ heweb2.aspx (accessed 26 May 2010).

Devine, J., and Egger-Sider, F. (2009). Going beyond Google: the invisible web in learning and teaching. London: Facet Publishing.

Downes, S. (2007). Places to go: Google's search results for "net generation". Innovate, 3 (4). [Online]. Available at: www.innovateonline.info/index.php?view=article\&id=455 (accessed 24 April 2008).

Rayner, J. (2008). Net-surfing lawyers warned of compliance risk. Law Society's Gazette, 12 June. [Online]. Available at: www.lawgazette.co.uk/news/net-surfing-lawyers-warned-compliance-risk (accessed 15 March 2010). 